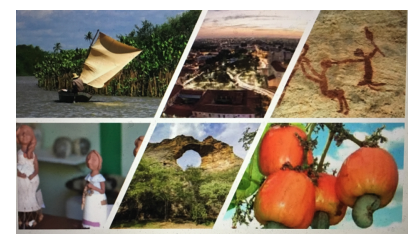

\title{
ESTUDO SOBRE DOCÊNCIA AMPLIADA NOS PROCESSOS DE ENSINO-APRENDIZAGEM BRASILEIROS
}

\author{
STUDY ON EXTENDED TEACHING AT THE BRAZILIAN \\ TEACHING-LEARNING PROCESSES
}

\author{
Arthur Vianna Ferreira \\ Universidade do Estado do Rio de Janeiro (UERJ) \\ Doutor em Educação: Psicologia da Educação - PUCSP. \\ Lattes ID: http://attes.cnpq.br/6209418269981786 \\ Marcio Bernardino Sirino \\ Professor da Universidade Castelo Branco \\ Doutorando em Educação pela Universidade do Estado do Rio de Janeiro \\ Lattes ID: http://lattes.cnpq.br/7948350545918651 \\ Patrícia Flavia Mota \\ Doutoranda em Educação \\ Universidade Federal do Estado do Rio de Janeiro (UNIRIO) \\ Lattes ID: http://attes.cnpq.br/3612338122550401
}

\begin{abstract}
RESUMO
O presente artigo tem como objetivo a ampliação do conceito de docência na formação inicial de professores em Licenciaturas. A partir da legislação brasileira (LDB de 1996, as Diretrizes Curriculares Nacionais para a formação dos professores de 2015 e o Plano Nacional de Educação de Direitos Humanos de 2007) torna-se obrigatório a preparação dos indivíduos para atuação em espaços não escolares. Assim sendo, o campo teórico da Pedagogia Social se apresenta como espaços formativos para estudantes de licenciaturas, de maneira especial, a Pedagogia da Convivência de Xesús Jares (2007) que valoriza as relações sociais estabelecidas entre educador no processo de ensino-aprendizagem em ambientes não escolares.
\end{abstract}




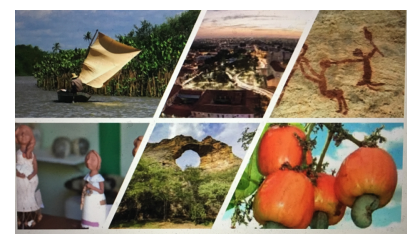

Palavras-chave: Formação docente inicial - Legislação Educacional Brasileira Pedagogia Social - Pedagogia da Convivência.

\begin{abstract}
This article searchs to expand the conception of initial teacher's courses. Based on Brazilian legislation (LDB - 1996, the National Curriculum for Teacher's Course - 2015 and the National Plan for Human Rights Education - 2007), it's important to prepare the students to work at non-school spaces. Therefore, The field of social pedagogy presents itself as a possibility of the special formation, especially the Pedagogy of the Coexistence of Xesús Jares (2007), which values the social relations established between educator in the teaching-learning process out of the school.

Keywords: Initial teacher's course - Brazilian Educational Legislation - Social Pedagogy - Pedagogy of Coexistence.
\end{abstract}

\title{
Introdução
}

Este artigo tem como objetivo demonstrar a importância da ampliação do conceito de docência na formação dos futuros educadores, dentro ou fora do ambiente escolar. Para esta discussão, trazemos a teoria da pedagogia da convivência, do autor catalão Xesús Jares, como uma ferramenta relevante no campo teórico da pedagogia social, para pensarmos as novas formas de organização didática na formação docente inicial ou continuada.

Assim, concretamente, a partir das reflexões suscitadas por essa teoria, podemos dar sentido ao que se encontra reconhecido como importante na formação docente para o início desse século XXI e que é apontado pela legislação educacional brasileira, tanto na LDB, de 1996, quanto nas diretrizes curriculares e planos de educação destinados à formação docente no país.

Por isso, as discussões trazidas por este artigo têm como intenção dar subsídios para as seguintes questões que se apresentam fundantes para a organização de um conceito de docência ampliada para a formação docente: a inclusão de teorias - e teóricos contemporâneos - da pedagogia social na formação docente inicial de professores que mostrem a importância das práticas já existentes em espaços não escolares; a pedagogia da convivência como exemplo de uma teoria que possa ser utilizada como ferramenta Revista Caminhos da Educação: diálogos, culturas e diversidades. CAEDU/UFPI

Teresina, Brasil, v. 1, n. 1, p. 174-193, janeiro/abril de 2019

DOI: 


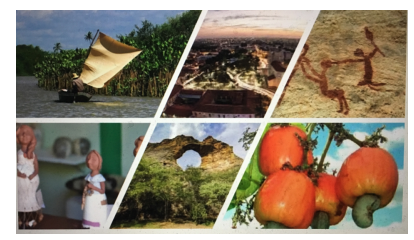

para a organização de didáticas no ambiente não escolar que levem em consideração, principalmente, o conflito como elemento central das relações interpessoais; e, o desejo de buscarmos novas posturas diante da realidade educacional em que nos encontramos o que refletirá na construção de uma identidade profissional docente diferenciada.

Estes três pressupostos parecem indicar que, a partir de nossa formação, podemos iniciar um processo educacional que atenda não somente às demandas dos sistemas educacionais e às políticas sociais impostas pelos governos, mas que, a partir da convivência entre os sujeitos educacionais, atendam às reais necessidades das camadas mais vulneráveis de nosso país e das instituições sociais que os acolhem em todas as suas dimensões.

Refletir sobre a formação docente, de forma ampliada e a pedagogia da convivência, como possibilidade de formação para práticas educativas não escolares, é o ponto inicial para a nossa leitura em pedagogia social.

\section{A convivência como elemento de práticas socioeducativas}

Para compreendermos a convivência como uma ferramenta eficaz para o processo de educação em ambientes não escolares, consultamos o minidicionário da língua portuguesa e, nesta busca, encontramos para o verbete 'convivência' a seguinte definição: 1. “Ação ou efeito de conviver; convívio. 2. Trato diário" (XIMENES, 2000, p. 255).

Dando continuidade à pesquisa, no verbo 'conviver' foi possível identificarmos a perspectiva de "Viver em comum, em graus variados de intimidade" (Ibid, p. 255). Esses significados podem nos direcionar para uma compreensão da convivência numa esfera do senso comum como sendo o ato de "estar com o outro", no entanto, faz-se necessário questionarmos, sempre, o que se faz no 'estar com o outro' e como se estabelecem esses vínculos.

Na certeza de que, na convivência com o outro, vamos construindo conhecimentos e estabelecendo espaços formativos, direcionamos o nosso olhar, nesta escrita, sobre a convivência não como um simples contato, mas sim como uma pedagogia - para espaços 


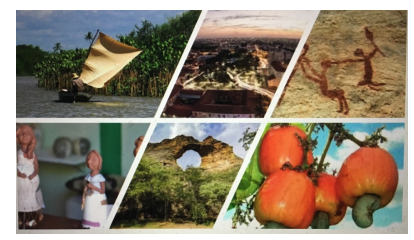

não escolares que, segundo Graciane (2011), "propõe reaprender a utilizar nossos espaços de interação para melhor compreender o outro e suas intenções" (p. 96).

Neste contexto, a "pedagogia da convivência" foi criada pelo educador catalão Xesús Jares, no ano de 2008, enquanto uma forma de estruturação do trabalho educativo perspectivando-se alcançar uma educação em direitos humanos e uma educação para a paz.

Jares quando criou a pedagogia da convivência, tendo como base uma experiência concreta de educação social construída no espaço escolar, buscou organizar reflexões sobre práticas socioeducativas com as características de 3 (três) tipos de conteúdos, conforme disponibilizamos a seguir: conteúdos de natureza humana: direito à vida e ao desejo de viver, à dignidade, à felicidade, à esperança; conteúdos de relação social: ternura, respeito, não violência, aceitação da diversidade e rejeição a qualquer forma de discriminação, solidariedade, igualdade; e, conteúdos de cidadania: justiça social e desenvolvimento, laicismo, estado de direito, direitos humanos (JARES, 2008, p. 29).

Estes conteúdos - de natureza humana, de relação social e de cidadania, ao serem trabalhados em espaços não escolares, contribuem para a promoção de uma educação em direitos humanos e uma educação para a paz que, segundo Jares (2002):

(...) estão tão intimamente interconectados que a realização de uns exige a realização dos outros. Atualmente, o chamado direito à paz, que faz parte da chamada terceira geração de direitos humanos (Jares, 1999), inclui e engloba praticamente todos os demais direitos humanos, visto que sua realização efetiva supõe a afirmação de todos os demais... A teoria da paz é, desse modo, a teoria dos direitos humanos (p. 129).

No entanto, para melhor caracterizar estas duas grandes 'teorias', trazemos o entendimento de educação em direitos humanos, como sendo aquela que "vai além de uma aprendizagem cognitiva, incluindo o desenvolvimento social e emocional de quem se envolve no processo ensino-aprendizagem" (BRASIL, 2007, p. 29) e, ainda, no que tange à promoção de uma educação para a paz, trazemos as contribuições de Jares (2002, p. 149) que nos afirma que "faz parte de educação em valores". 


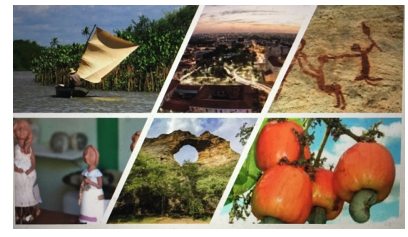

Neste contexto, se faz necessário evidenciar que, por meio da pedagogia da convivência, estes 'conteúdos' são trabalhados e a busca por uma educação em direitos humanos e uma educação para a paz é materializada e potencializada em espaços não escolares.

Os relatos dos benefícios deste trabalho pedagógico no atendimento das demandas educacionais e sociais dos grupos juvenis da Catalunha foram sistematizados em um conjunto de fundamentos que organizam essa pedagogia da convivência.

Para sintetizar e melhor facilitar a compreensão acerca desses fundamentos, Autor (2018) elaborou um quadro com os "elementos da pedagogia da convivência", que dispomos a seguir.

Quadro 1- Elementos da Pedagogia da Convivência.

\begin{tabular}{|c|c|}
\hline 1- Respeito & Supõe a reciprocidade no trato e no reconhecimento de cada pessoa. \\
\hline 2-1 & $\begin{array}{l}\text { O diálogo é também um fator essencial para dar e melhorar a qualidade } \\
\text { de vida das relações humanas. }\end{array}$ \\
\hline $\begin{array}{c}\text { 3- } \\
\text { Solidariedade }\end{array}$ & $\begin{array}{l}\text { Qualidade que nos leva a partilhar os diferentes aspectos da vida, não } \\
\text { somente materiais, mas também os sentimentos. }\end{array}$ \\
\hline violência & $\begin{array}{l}\text { A violência é uma forma de encarar os conflitos, mas não de resolvê- } \\
\text { los. Princípio fundamental de respeito à vida dos demais, a vivência dos direitos } \\
\text { humanos, os princípios democráticos de convivência e a prática das estratégias } \\
\text { não violentas de resolução de conflitos. }\end{array}$ \\
\hline 5- Laicismo & $\begin{array}{l}\text { Representa a garantia da liberdade de consciência e da igualdade } \\
\text { jurídica de todos os cidadãos. }\end{array}$ \\
\hline $\begin{array}{l}\text { 6- Dinâmica } \\
\text { da Cultura }\end{array}$ & $\begin{array}{l}\text { A cultura é um processo dinâmico ligado às próprias condições de vida } \\
\text { das pessoas e, como tal, incide na vida destas e vice-versa. }\end{array}$ \\
\hline 7- Ternura & $\begin{array}{l}\text { A afetividade é necessidade fundamental de todos os seres humanos. } \\
\text { É a necessidade que nos torna humanos, indispensável à construção equilibrada } \\
\text { da personalidade. }\end{array}$ \\
\hline
\end{tabular}




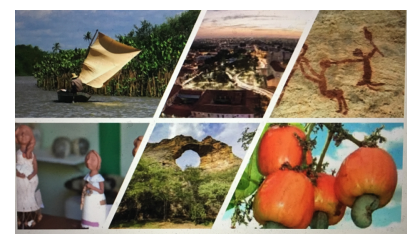

\begin{tabular}{|c|c|}
\hline erdão & $\begin{array}{l}\text { Perdão não significa impunidade. A condição do perdão para quem o } \\
\text { solicita é o reconhecimento da falta, o arrependimento e o compromisso de que } \\
\text { não voltará a cometer a mesma ação. }\end{array}$ \\
\hline $\begin{array}{c}\text { 9- } \\
\text { Diversidade }\end{array}$ & $\begin{array}{l}\text { Conviver significa conjugar a relação de igualdade e diferença. Em } \\
\text { todo o caso, a diferença ou diversidade é parte da vida e pode ser um fator de } \\
\text { conflituosidade. }\end{array}$ \\
\hline $\begin{array}{l}\text { 10- Bem- } \\
\text { Estar: } \\
\text { Felicidade/Esperança }\end{array}$ & $\begin{array}{l}\text { A felicidade é a capacidade de encantar-se, de ter entusiasmo pela vida. } \\
\text { A esperança está ligada ao otimismo e, neste sentido, facilita a convivência } \\
\text { positiva, com efeito benéfico para a autoestima, individual e coletiva, e funciona } \\
\text { como um antídoto frente à passividade e o conformismo diante dos desafios. }\end{array}$ \\
\hline
\end{tabular}

Fonte: Autor (2018).

Temos a clareza de que todos estes 10 (dez) elementos são importantes e carecem de atenção especial no que tange à sua relação com os conteúdos - de natureza humana, de relação social e de cidadania - apresentados anteriormente.

Pois, quando nos deparamos com a aceitação da "diversidade", a prática do "perdão" e a busca pelo "bem-estar", encontramos conexões com os conteúdos da natureza humana; de igual forma acontece quando problematizamos a "dinâmica da cultura", desenvolvemos a prática de "ternura" e o hábito do "diálogo", pois, percebemos encontros significativos com os conteúdos de relação social e, por fim, quando exercemos o "respeito", desenvolvemos a "solidariedade", buscamos pela "não violência" e, ainda, valorizamos o "laicismo", diretamente, identificamos uma relação com os conteúdos da cidadania - processos educativos estes que não são lineares, mas que se correlacionam o tempo todo, por meio da pedagogia da convivência, na certeza de que "conviver também é educar".

Como um exercício de exemplificação e aprofundamento das reflexões no que tange à temática proposta para este artigo, a partir do quadro 1- "elementos da pedagogia da convivência" temos a oportunidade de perceber, por meio do elemento da "não violência" e a sua descrição, uma correlação entre a violência e sua perspectiva de resolução/mediação de conflitos. 


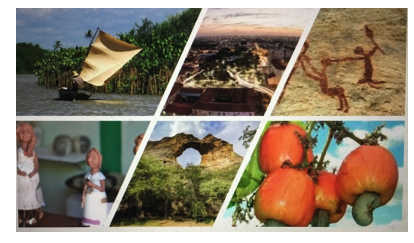

Aspecto tão necessário na contemporaneidade, uma vez que, em diferentes espaços socioeducativos, os processos conflituosos acontecem, cotidianamente, e, por vezes, 'desagregam' a convivência humana - trazendo, como consequência, soluções violentas atreladas à forma como o conflito é percebido pelos sujeitos.

Neste sentido, reforçamos a importância de buscar, a cada dia, soluções não violentas para os conflitos apresentados nos diferentes espaços sociais, a começar pela diferenciação atribuída ao conceito de "violência" do próprio conceito de "conflito", conforme Xesús Jares, citando Sémelin (1983) nos orienta.

É necessário diferenciar a agressão ou qualquer resposta violenta de intervenção em um conflito do próprio conflito. A confusão ocorre porque iguala-se violência a conflito. Quando a violência é apenas um dos meios de resolver o conflito, destruindo o outro. A violência tende a suprimir o conflito, apontando para a eliminação do adversário. A violência é um meio, o conflito é um estado de fato. (JARES, 2002, 141)

Neste sentido, a convivência construída entre os sujeitos inseridos nos diferentes espaços socioeducativos estarão contribuindo para uma relação social mais humanizadora ou promotora de menos violência? Nas leituras de Jares, talvez, possamos entender o conflito como um termômetro do processo de convivência.

\section{A relevância do conflito no processo da convivência educacional segundo Jares}

A partir dos estudos de Xesús Jares (2002, 2005, 2007 e 2008) vimos observando uma perspectiva positiva para os conflitos ao relacioná-los a um processo natural, necessário e, potencialmente, positivo para as pessoas e os grupos sociais. Desta forma, a pedagogia da convivência se nos apresenta como uma forma - político-pedagógica - de trabalhar os conflitos por meio de uma educação em direitos humanos objetivando contribuir na materialização de uma educação para a paz.

No meio de um terrorismo global, terrorismos locais e degradação social, o que podemos fazer para pensar os conflitos presentes nos nossos contextos e perceber a potencialidade que neles habita? 


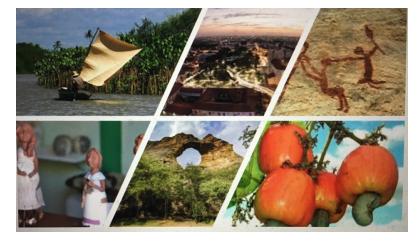

Questão sine-qua-non nesta sociedade contemporânea, que carece de uma ênfase maior no valor da vida humana, da dignidade de todas as pessoas e, ainda, da cultura da não violência, da paz e da solidariedade, como nos propõe Xesús Jares (2005).

Para respondermos esta questão é importante que, antes, dinamizemos a compreensão sobre educação para a paz - uma vez que com clareza desta concepção de educação, teremos condições de compreender o processo natural de construção dos conflitos.

Segundo Jares (2002), educação para a paz é:

Um processo educativo, dinâmico, contínuo e permanente, fundamentado nos conceitos de paz positiva e na perspectiva criativa do conflito, como elementos significativos e definidores e que, mediante a aplicação de enfoques socioafetivos e problematizantes, pretende desenvolver um novo tipo de cultura, a cultura da paz. (p. 148)

Educação para a paz possui 3 (três) modelos sistematizados, a saber: técnicopositivista, hermenêutico-interpretativo e sociocrítico. Sintetizados, a seguir, a partir das contribuições de Jares (2002, p. 145 a 147).

a) Técnico-positivista, como uma perspectiva que transmite um ideal de educação neutra, sem conflito e que a educação para a paz tem uma materialidade observável e mensurável;

b) Hermenêutico-interpretativo, como um viés de educação para a paz que evita na mente - os conflitos como uma forma de criar um mundo utópico sem violência;

c) Sociocrítico, um caminho que percebe de maneira crítica o conflito, analisa suas diferentes dimensões formadoras, não se impõe 'neutra' pois está relacionada com a transformação das estruturas violentas justamente com resoluções não violentas para os conflitos apresentados.

Sobre estas três perspectivas, Jares (2002) destaca que:

Não é preciso dizer que, como em toda classificação, existem características que podem se enquadrar em diferentes categorias e, em segundo lugar, ocorrem outros fatores 


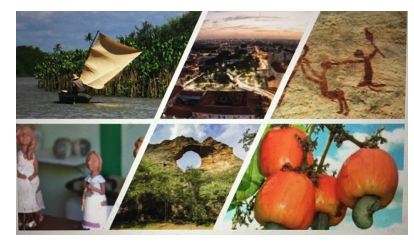

que costumam dificultar a classificações anteriores, como a) a amplitude que se atribui a cada uma delas com relação a seus currículos ou objetos de estudo - enfoques amplos ou restritos; b) a temporalização e c) prioridade dos objetivos - quais objetivos a curto prazo e quais objetivos a médio e a longo prazos (p. 147).

Percebam que a compreensão de educação para a paz não é unânime. Ela possui suas diferentes visões sociais e formas de compreensão que, inclusive, por vezes, aglutina características comuns a diferentes categorias.

De igual maneira acontece com o conceito de conflito. Analisando, novamente, as contribuições do minidicionário da língua portuguesa, encontramos para este verbete a seguinte definição: “1. Luta, briga. 2. Guerra. 3. Choque, colisão (de interesses, ideias etc.). 4. Desavença séria" (XIMENES, 2000, p. 241).

Percebam que a definição de 'conflito', inserido no minidicionário, se alinha a uma compreensão do senso comum que iguala conflito a "qualquer resposta violenta" (JARES, 2002, p. 141).

Entretanto, de acordo com Xesús Jares (2002), o conflito possui duas perspectivas, tais quais: 1) Perspectiva tradicional que considera o conflito como algo negativo e associado à violência; e, 2) Perspectiva positiva que - alicerçado numa teoria crítica da educação e pesquisa para a paz - se configura num processo natural, que estimula a criatividade, percebe o conflito como um novo desafio e, consecutivamente, está relacionado à mudanças nas relações.

No que tange à perspectiva tradicional, Jares (2002) sinaliza que o conflito é considerado como:

Sinônimo de desgraça, de má-sorte, conflito como algo patológico ou aberrante; como disfunção; etc. A consequência desse estado de coisas é que o conflito é uma situação a ser evitada ou pelo menos é algo não-desejável. Infelizmente, o conflito costuma ser percebido quase unicamente em termos negativos (p. 132). 


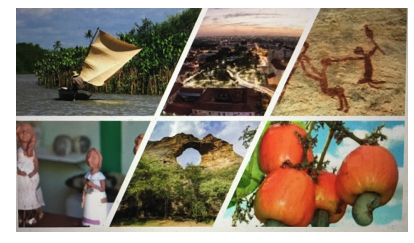

Por sua vez, sobre a perspectiva positiva, Jares (2002) destaca que o conflito é percebido como:

Em primeiro lugar, o conflito é consubstancial e inevitável à existência humana (p. 134). Em segundo lugar, é um processo natural e necessário em toda a sociedade humana, é uma das forças motivadoras da mudança social e um elemento criativo essencial nas relações humanas (p. 134). E, por fim, em terceiro lugar, o conflito é um desafio, tanto intelectual quanto emocional para as partes envolvidas (p. 135).

Mas, por mais que tenhamos o entendimento da perspectiva positiva do conflito como uma possibilidade de fortalecer à dimensão estrutural e individual dos sujeitos, temos a clareza do quanto é difícil dinamizar processos conflituosos, justamente, pelo conflito, por vezes, focar na dimensão estrutural das organizações e instituições, outras vezes, por percebermos um alinhamento com as condutas individuais dos integrantes do grupo social e, ainda, por combinar ambos enfoques - em espaços escolares e não escolares, exigindo, por sua vez, de uma compreensão mais ampliada sobre a estrutura que sustenta o próprio conflito.

Com as contribuições de Jares (2002, p. 138-141), conseguimos identificar a seguinte estrutura do conflito - composta por 4 (quatro) partes, a saber: 1 - causas que o provocam; 2- protagonistas que intervêm; 3- o processo que se seguiu e, por fim, 4contexto no qual se produz. Para melhor problematizar esta estrutura, apresentamos, a seguir, cada um destes alicerces.

Sobre o primeiro - causas que o provocam - podemos considerar que o conflito se estrutura, muitas vezes, por conta de oposições pedagógicas, ideológicas ou organizacionais, relacionadas ao poder, à estrutura ou, ainda, com questões pessoais e de relação interpessoal.

Referente ao segundo alicerce - protagonistas que intervêm - é possível afirmar que o conflito se estrutura por meio de dois protagonistas, tais quais: protagonistas 'diretos' que possuem uma relação específica com as causas que provocam o conflito e 


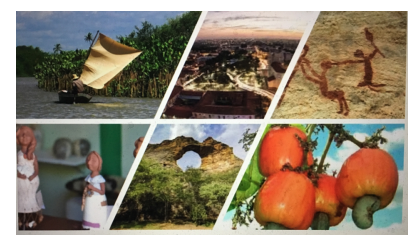

protagonistas 'indiretos' que, mesmo inseridos na origem do conflito, em algum momento intervém no mesmo.

No que tange ao terceiro - o processo que se seguiu - convém destacar que diversas variáveis influenciam para o estabelecimento de um conflito. Pode ser a questão dos valores de cada um, o tempo disponível ou vivenciado, as normas impostas pelos espaços, os interesses individuais e coletivos e, dentre outras, as pressões pelas quais vivem ou sofrem os sujeitos. Cada uma dessas dimensões vai contribuindo para estruturar o conflito.

Por fim, o quarto e último alicerce - o contexto no qual se produz - traz uma discussão necessária sobre o conflito como uma conduta cultural, pois o conflito se estrutura num contexto sociocultural determinado e este contexto produz o conflito, justamente, por sua dimensão cultural ali inserida.

Neste contexto, ao pensarmos no conflito, dentro do processo educacional, poderemos tratar as práticas socioeducativas de forma menos pessoal e mais coletiva, entendendo que as relações sociais por si mesmas elas são conflituosas.

\section{Contextos conflituosos nos processos educacionais não escolares: o caminho} para a convivência

Após introduzirmos os conceitos de convivência, expressa na teoria de Jares, e o conflito, como parte do trabalho da utilização dessa ferramenta, cabe-nos entender de que forma podemos articular essa teoria a nossos trabalhos sociopedagógicos ou, minimamente, pensarmos sobre eles a partir dessa perspectiva.

Por isso, como caso exemplar, apresentamos de forma muito breve e esquemática parte dos resultados de uma pesquisa desenvolvida pelo nosso grupo de estudos, pesquisa e extensão intitulado fora da sala de aula, da faculdade de formação de professores da Universidade do Estado do Rio de Janeiro (UERJ), campus São Gonçalo, e que busca pensar esse espaço socioeducativo como um espaço de aprendizagem a partir dos seus sentidos e significados nos processos de convivência socioeducativa. Esse trabalho foi 


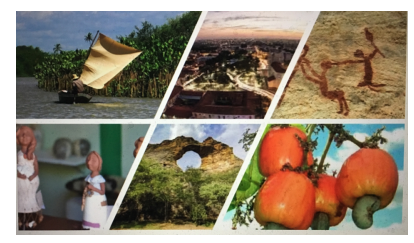

apresentado no Seminário Interuniversitário de Pedagogia Social, em Palma de Mallorca, Espanha, em novembro de 2018.

A investigação levada a cabo no município de São Gonçalo, intitulada “TÍTULO”, que teve como objetivo geral discutir sobre a inclusão do campo teórico da pedagogia social na formação docente inicial e/ou continuada no ensino superior no Brasil, buscou trazer em consideração a pedagogia da convivência apregoada por Jares como um dos elementos fundantes para se pensar o papel do pedagogo e/ou docente em licenciaturas no país.

A valorização dos elementos da pedagogia da convivência (cf. Autor, 2018) para pensar o lócus de trabalho docente não curricular formal, estabelecido pelas diretrizes e currículos mínimos nacionais, se apresenta como fonte de novas metodologias e possíveis práticas socioeducativas nos quais os educadores dedicados ao processo educacional não escolar podem não somente pensar na sua prática, mas, também, nas demandas oriundas dos grupos sociais em situação de vulnerabilidade.

Assim sendo, as principais estratégias utilizadas para a inclusão dos conteúdos (e temas) da pedagogia social na formação docente inicial foram articuladas da seguinte forma: nos trabalhos de extensão universitária que promoveram o encontro entre os estudantes e os educadores socais que se encontram no campo de trabalho (entre 2017 e 2018 na UERJ), possibilitando, assim, a troca de experiências e de inquietações que a convivência socioeducacional tenciona no trabalho com os mais empobrecidos; e, a possibilidade de inclusão das discussões temáticas pertinentes a esse campo de estudo através de disciplinas do currículo regular de licenciaturas a partir de 2017 (Didática, Psicologia da Educação e Psicologia Social) trazendo temas cotidianos em que se encontram a realidade social brasileira e de que forma, a partir da especificidade dos fundamentos da educação, o docente possa contribuir para esse trabalho.

De fato, ao propormos a pedagogia da convivência, como parte do processo formativo docente regular, estamos entendendo a importância do que Jorge Larossa 


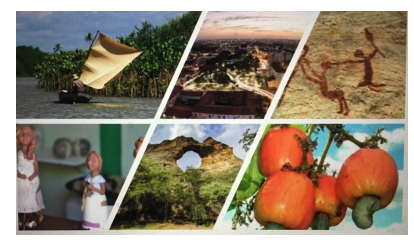

(2002) entende como 'hetero-auto-bio formação' dos indivíduos em seus processos educacionais.

Ou seja, os processos formativos com os indivíduos são introduzidos pelas relações sociais ordinárias, por meio das diversas instituições existentes (heteroformação), deve levar ao sujeito a uma autonomia que o faça entender quais os melhores caminhos a serem traçados em seu processo individual de formação para que a realidade concreta faça sentido para si mesmo e para os demais (autoformação).

Tudo isso, não se desenvolve sem a presença de um espaço concreto, real e cheio de conflitos que obrigue ao indivíduo a tomar posicionamentos diante dele a partir do que foi construído tanto pela hetero quanto autoformações.

A bioformação é um elemento fundamental no processo constituinte do serdocente em qualquer espaço educacional e, de maneira mais especial, em espaços socioeducativos.

Neste contexto, os conteúdos propostos por Jares (2008, p. 29) a serem trabalhados no processo da convivência educacional são importantes para o futuro docente. Os conteúdos de natureza humana, expresso nas diferentes disciplinas de fundamentos dos cursos de formação professores podem ser um conjunto de reflexões válido para pensarmos, não somente naquilo que é comum a todos os seres humanos, mas, também, o que se apresenta como necessidades básicas a um contingente populacional que se apresenta fora dos parâmetros minimamente aceitáveis na sociedade contemporânea e que se encontram a nosso encargo no ambiente educacional.

Os conteúdos de natureza relacional (JARES, 2008, p. 29), fruto da construção formativo do ser humano se apresentam como quase resultado final da reflexão sobre os conteúdos da natureza. Ao pensar a humanidade em suas dimensões antropológicas, filosóficas, psíquicas, entre outras, o educador em processo de formação é convidado a questionar sobre elementos importantes e constituintes do ser humano (como ternura, afetividade, diálogo, bem estar etc.) e que são vivenciados somente em coletividade, ou seja, na relação que estabelecemos nos pequenos e grandes grupos sociais. 


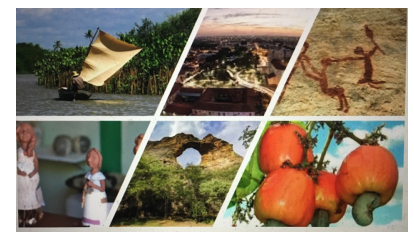

Assim sendo, o trabalho clamado por Jares, na sua pedagogia da convivência, passa a ser uma das bandeiras da formação docente inicial e continuada para o trabalho em ambientes educacionais escolares ou não: a educação para os direitos humanos.

Neste sentido, temos em Jares (2002) um dos seus maiores propagadores, pois, para este autor, o projeto de educação para a paz está totalmente pautado na possibilidade de entendermos as motivações histórico-sócio-filosóficas que nos comprometem a uma educação para e nos direitos humanos, independente do que tenha sido feito daquela vida a qual temos diante de nós e que, por semelhança biológica, psíquica e, consequentemente, social, chamamos de 'humanos'.

Ao trazer a pedagogia social para a formação docente, reafirmamos o estudo aprofundado dos direitos humanos como um dos conteúdos da relação social mais importante e que vai ser basilar para o terceiro, e contínuo, conteúdo constituinte da construção da pedagogia da convivência que são os conteúdos da cidadania.

Na verdade, o que Jares coloca como conteúdos da cidadania (Jares, 2008, p. 29), presentes na pedagogia da convivência, já se encontra como elementos marcantes da nossa formação docente nesse país. A lei de diretrizes e bases da educação nacional, Lei 9.394, de 1996; as diretrizes curriculares de pedagogia, de 2006, e as diretrizes curriculares de licenciaturas, de 2015, trazem no conjunto de seus parágrafos e dispositivos o conceito de cidadania, seus desdobramentos e a importância da formação docente tê-los bem articulado em seu conjunto de teorias a serem refletidas na sua formação inicial e continuada.

Além disso, o Brasil possui um plano nacional de educação e direitos humanos (PNEDH), de 2007, que institui não somente as diretrizes para esse tipo de educação, promotora de paz como recorda Jares (2002), não somente para o sistema escolar, mas também para o sistema de educação não escolar (cf. BRASIL, 2007, p. 43).

Ou seja, os conteúdos propostos pela pedagogia da convivência se configuram como elementos fundantes da formação docente para além dos conteúdos programáticos estabelecidos pelos currículos mínimos formais. A convivência é o campo da relação 


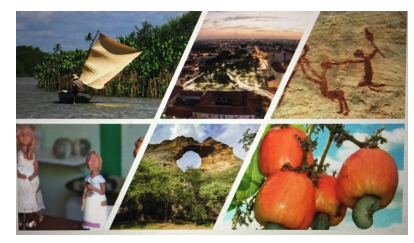

educacional, escolar e não escolar, que se produz no cotidiano e que se transforma a partir das necessidades dos grupos envolvidos nos processo educacionais.

Sendo dessa forma, a introdução da pedagogia social na formação docente, pode contribuir para a reflexão de um elemento intrínseco à convivência: o conflito. Desta forma, a pedagogia da convivência, como organizada por Jares, nos auxilia na capacidade de formar os indivíduos responsáveis pela formação docente de forma ampliada (ou seja, na escola ou fora dela) para compreender os conflitos intrínsecos nas relações de convivência, não com o sentido de resolvê-los, porém, com o desejo de incorporá-los à prática docente cotidiana que auxiliará o sujeito no seu processo, individual e coletivo, de ser-no-mundo por meio da educação.

Partindo deste pressuposto, a decodificação dos conflitos existentes no ambiente educacional (cf. Jares, 2002, p.138) em quatro partes (causas, protagonistas, processos e contextos) passa a ser mais uma ferramenta a mais para que o futuro educador ascenda à compreensão de como o trabalho da convivência está sendo organizado pelo grupo social no qual ele se faz responsável (e, por isso, também se encontra como parte crucial da convivência) se organiza e produz conflitos entre os diversos sujeitos e seus grupos de pertença.

Assim, o educador conseguirá enfrentar os conflitos do processo educacional de forma um pouco mais consciente de suas potencialidades e limitações e articulando os fundamentos aprendidos ao longo de sua formação e/ou articulando redes de trabalho que possam ajudar, não a resolver os conflitos em si - pois esse não é o objetivo principal do trabalho da convivência - mas, sim proporcionar uma educação para a paz, que para Jares (2002, p. 164-165), será a possibilidade de vivermos as diferenças sociais e pessoais, administrando os conflitos existentes na convivência e promovendo os valores fundamentais que não devem ser negados a nenhum dos seres humanos, independente da sua relação étnica-racial-sexual-social-econômica, e por que não dizer, educacional. 


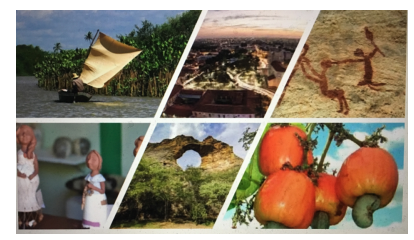

Os resultados desta investigação nos ajudam a desenhar um panorama de formação docente ampliada (inicial e continuada), a partir da introdução desses elementos da pedagogia social como convivência nos estudos de Jares (2002, 2005, 2007).

\section{Formação docente ampliada (Escolar e não Escolar)}

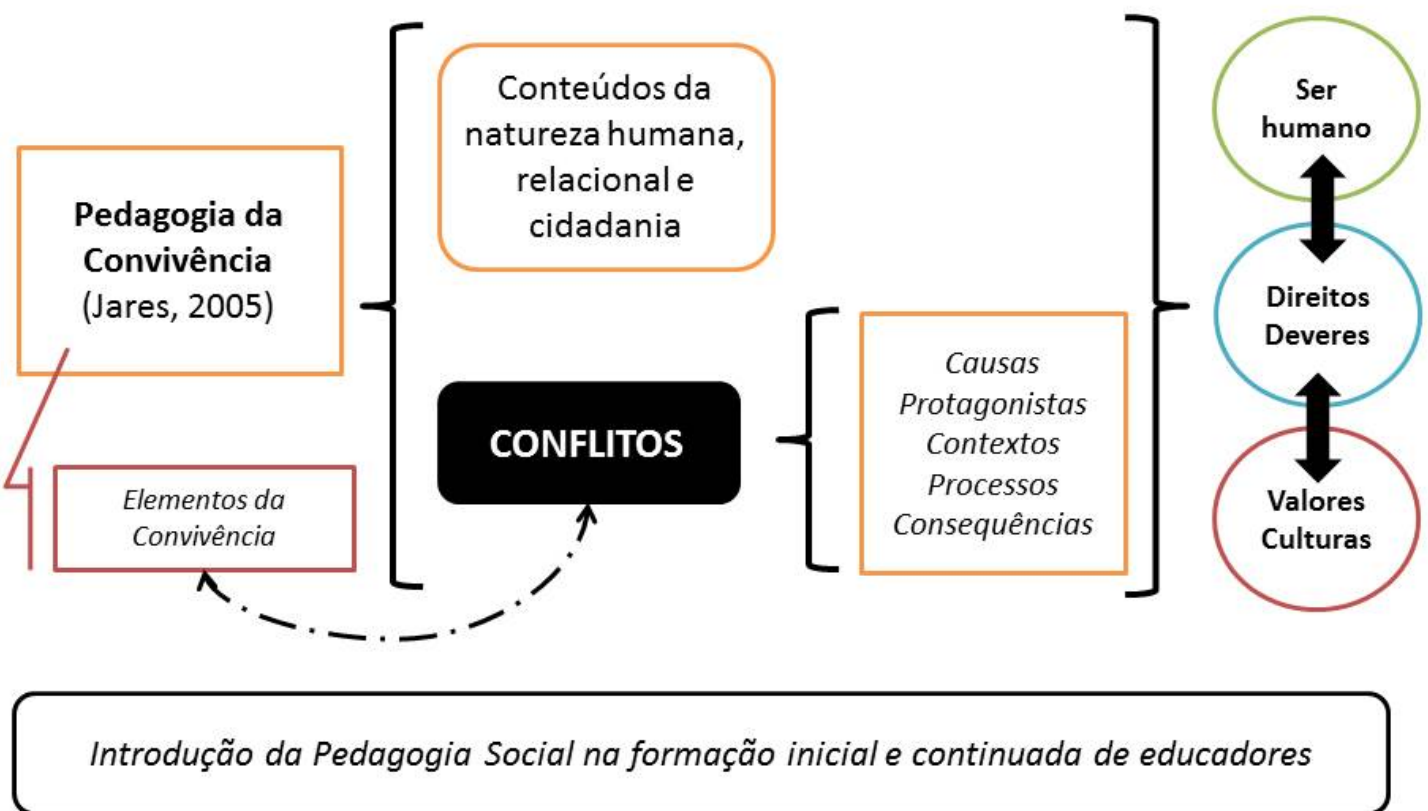

Quadro 2: O local da reflexão do conflito na organização da formação docente inicial e continuada para trabalhos socioeducativos

Fonte: Elaborado pelos Autores (2019).

A introdução da pedagogia da convivência e a reflexão, que deve ser aprofundada, dos conceitos entrelaçados por esse autor, devem nos ajudar, primeiramente, a nos situar no ambiente educacional não escolar (ou escolar) de conteúdos que nos levam a formação do nosso ser como humanos que, ao viver os elementos mínimos propostos pela convivência entre os indivíduos e grupos distintos, trazem o conflito como um dos elementos de sua chave. 


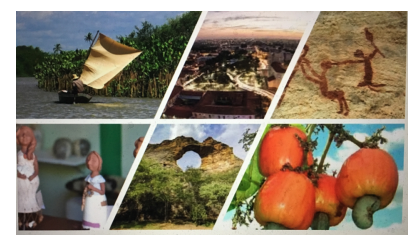

A partir da decodificação deste elemento em destaque - não pelo seu caráter desagregador, mas pela sua possibilidade de retroalimentar os elementos próprios da convivência - podemos dialogar, construir, negociar, demandar, articular e criar todos os tipos de valores, culturas, direitos, deveres que sustentaram a nossa existência humana em todas as suas dimensões (bio-psico-social), principalmente, quando esses grupos se veem destituído de condições para, no conflito promovidos pela convivência, serem destruídos, humilhados e até mesmo eliminados do convívio social.

\section{Concluindo parcialmente uma discussão sobre a docência que precisa ser} ampliada

A docência deve ser pensada sempre de forma ampliada. Isso significa na sua diversidade de elementos a serem pensados no momento da organização didática de seus conteúdos, assim como nos locais de realização da educação. Pensar que a escola pode ser o único local de exercício da docência é regredirmos aos conceitos escolares medievais que tanto lutamos para que fossem derrubados na sociedade contemporânea.

Pensar em formação docência, apenas como sinônimo de 'escola', é levantar muros em um tempo histórico no qual precisamos construir pontes. E os responsáveis pela formação de novos formadores devem levar em consideração essa realidade na hora de organizar sua didática, que não será somente voltada para o que acontece dentro da escola, mas, também, deve levar em consideração as outras instituições sociais que solicitam de nós, os especialistas da educação, uma postura sobre como organizar as rotinas de aprendizagem necessárias para a formação do ser humano em sociedade.

É, por isso, que este artigo encontra seu sentido maior: suscitar em cada dos leitores o desejo de se colocar nessa seara. A legislação educacional brasileira, as diretrizes curriculares nacionais e os planos educacionais organizados até o presente momento mostram o reconhecimento, nas políticas públicas, de que o espaço socialmente reconhecido como educacional não pertence somente à escola (embora ela continue sendo 


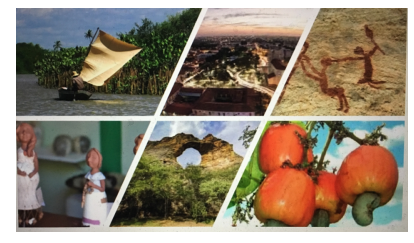

o espaço privilegiado e necessário de articulação de conhecimentos científicos e de patrimônio cultural no ocidente).

As instituições e suas relações sociais são locais verídicos de formação humana e de educação que gera a convivência fundante de quaisquer práticas educacionais de origem acadêmica e científica.

Ocupar esse espaço é o desafio dos indivíduos que escolhem a docência como identidade profissional na sociedade brasileira. A relevância do estudo de Xesús Jares pode se encontrar nesse aspecto da formação: a partir da convivência entre os indivíduos, nos ambientes não escolares, vamos acentuando a forma com a qual vamos construindo a nossa identidade profissional como educadores, que não possuem mais a escola como o único espaço de formação dos indivíduos.

Ao contrário, valorizamos a nossa formação e os conteúdos programáticos da formação docente inicial e continuada quando somos capazes de articulá-los com a realidade concreta fora do ambiente escolar, possibilitando os processos educacionais aplicáveis aos diversos espaços institucionais em que somos convidados a participar com nossas práticas educativas.

Até o presente momento, a partir dos estudos que estão sendo realizados, uma das contribuições importantes da pedagogia da convivência para a formação docente, inicial e continuada, é levar em consideração o conflito como parte do processo educacional, principalmente os que se referem às relações interpessoais entre os educadores e educandos - tão valorizados pelos espaços educacionais não escolares. Ao tentar decompor os conflitos em suas quatro partes, essa pedagogia busca dar mais subsídios para o profissional da educação em formação, inicial e continuada, para que possa entender melhor sua função identitária em espaços não escolares, assim como organizar a didática nesses mesmos espaços de forma a atender as demandas dos seus educandos.

O convite que se realiza ao trazermos a pedagogia da convivência no campo da pedagogia social é continuarmos a construir possibilidades de reinvenção das nossas práticas nos espaços socioeducacionais do país. Os limites que marcam a educação em 


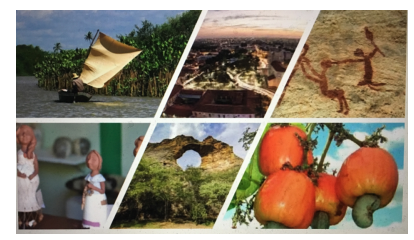

espaços não escolares não se apresentam tão definidos como gostaríamos que estivessem em nosso contexto social. O que se apresenta para nós é uma longa carta de intenção de práticas educativas não escolares e, consequentemente, a construção da identidade docente não escolar.

Cabe a cada um de nós, responsáveis pela formação docente, ampliarmos as potencialidades de nossa atuação. Talvez, essa seja o nosso primeiro conflito a ser enfrentado como profissionais da educação convencidos, ao longo da história da formação docente brasileira: que o nosso local se restringe, apenas, ao ambiente escolar. Ou pior, que não somos capazes de ocupar outros espaços sociais que reconhecem - e precisam - dos nossos conhecimentos na área dos fundamentos da educação para articulálos com a realidade social de vulnerabilidade em que se encontram parte de nossos educandos.

\section{Referências Bibliográficas}

BRASIL. Plano Nacional de Educação em Direitos Humanos. Brasília: Secretaria Especial dos Direitos Humanos, Ministério da Educação, Ministério da Justiça, UNESCO, 2007.

GRACIANI, Maria Stela Santos. A formação do educador social e a Pedagogia da Convivência. In: RAMOS, Marcos Fadaneli; ROMAN, Artur. Educadores Sociais: a Importância da formação na implementação de tecnologias sociais. Brasília, DF: Fundação Banco do Brasil, 2001. 


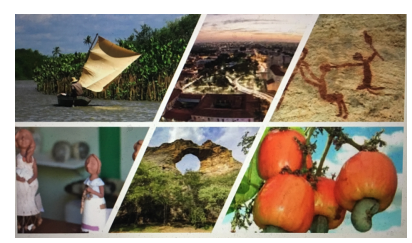

JARES, Xesús. Educação para a Paz: sua teoria e sua prática. Porto Alegre: Artmed, 2002.

_. Educar para a paz em tempos dificeis. São Paulo: Pala Athenas, 2007.

. Educar para a verdade e para a esperança. Porto Alegre: Artmed, 2005.

. Pedagogia da Convivência. São Paulo: Pala Athenas, 2008.

LARROSA, Jorge. Notas sobre a experiência e o saber de experiência. Revista Brasileira de Educação, Campinas, n. 19, p. 20-28, jan./abr. 2002.

XIMENES, Sérgio. Minidicionário Ediouro da Lingua Portuguesa. São Paulo: Ediouro, 2000 